\title{
LEFEBVRE, Henri. Espaço e política. Belo Horizonte: Ed. da UFMG, 2008, $192 \mathrm{p}$.
}

\author{
Marcos Leandro Mondardo - Universidade Federal da Bahia - Barreiras - Bahia - Brasil \\ marcosmondardo@yahoo.com.br
}

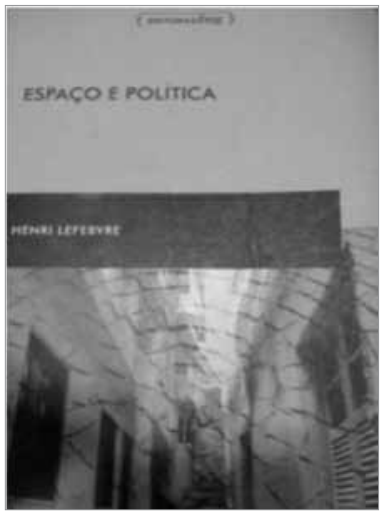

Espaço e política é um livro que reúne uma coletânea de artigos do filósofo Henri Lefebvre originalmente publicados em 1972 na França, ${ }^{1}$ contendo uma seminal análise e discussão "teórica" a respeito da produção do espaço e, notadamente, sobre o espaço urbano e a cidade. $\mathrm{O}$ autor propõe a elaboração de uma teoria sobre a problemática do espaço (teoria, aliás, que viria desenvolver mais a fundo em livro posterior), ${ }^{2}$ na qual busca desenvolver uma análise da totalidade dos elementos que produzem o espaço a partir da teoria marxista.

O livro contém sete artigos, dentre os quais podemos agrupar as discussões em duas perspectivas (não diacrônicas, mas sincrônicas) da teoria/problemática da espacialidade.

Na primeira parte do livro, percebe-se que os três primeiros artigos - "O espaço", "Reflexões sobre a política do espaço" e "A cidade o urbano" - apresentam uma discussão mais "teórica", do ponto de vista da conceituação do espaço mediante a construção de hipóteses sobre a "produção do espaço", de sua definição e conceituação. Concebe, então, uma reflexão filosófica acerca da "reprodução das relações sociais de produção", em sentido amplo, por meio da construção do espaço urbano e da cidade na sua forma-conteúdo material e vivida. Assim, para o autor, produção significa também e sobretudo criação. Criação de obras (tempos e espaços incluídos) pelos e para os homens nas e pelas quais possam realizar e reconhecer a trajetória da formação do ser humano.

Na segunda parte estão concentrados os quatro últimos artigos: "Engels e a utopia", "As instituições da sociedade pós-tecnológica", "A burguesia e o espaço", "A classe operária e o espaço", em que o autor faz uma análise das "variáveis" que produzem o espaço, como as instituições, a burguesia, as classes e a utopia, cada qual com suas relações, conflitos, lutas e contradições. 
Para Lefebvre, houve transformações na maneira como a cidade foi produzida na sociedade tradicional e como passou a ser construída na sociedade capitalista. Nessa última, segundo o autor, passa-se da produção das coisas no espaço à produção do espaço planetário. Avança-se da consideração clássica dos lugares de implantação industrial para o espaço inteiro, ou seja, ocorre uma mutação, pois o espaço (e não as coisas no espaço) é que passa a ser produzido, agora, em escala planetária, sendo por isso a mais-valia o motor dessa relação social mundial.

Lefebvre menciona que existem vários métodos e abordagens no que concerne ao espaço, e isso em diferentes níveis de reflexão, de recorte da realidade. Para ele, por exemplo, pode-se estudar o espaço percebido, isto é, aquele da percepção comum à escala do indivíduo e de seu grupo, a família, a vizinhança, aí compreendendo o que se chama de ambiente. Uma das hipóteses levantadas é aquela que concebe o espaço como resultado do trabalho e da divisão do trabalho, pois ele é o lugar geral dos objetos produzidos, o conjunto das coisas que o ocupam e de seus subconjuntos, efetuado, objetivado, sendo portanto funcional de acordo com um conjunto ou setor de atividade. O espaço é, amiúde, o objetivo, ou melhor, a objetivação do social, das relações que a sociedade materializa a partir de uma intencionalidade.

Por isso, para o autor, o espaço tornou-se instrumental. Lugar e meio onde se desenvolvem estratégias, onde elas se enfrentam, o espaço deixou de ser neutro, geográfica e geometricamente, há muito tempo. Logo, o espaço não é neutro e nem inofensivo; pelo contrário, está - como considera Lefebvre - sendo cada vez mais instrumentalizado, ganhando novas formas, conteúdos e significados para se tornar estratégico, dotado de intencionalidades para ser utilizado como meio para se atingir a "dominação". O espaço produzido é, portanto, o espaço projetado.

Em outra hipótese, o autor afirma que o espaço é significante, e comporta significados que são dotados de experiências e sentidos que produzem/influenciam nossos comportamentos. Trata-se daquilo que Lefebvre chama de espaço vivido, vinculado à prática social. Esse espaço vivido, também chamado pelo autor de mental, gera o espaço social que está relacionado às estratégias desenvolvidas na cidade. Dessa forma, hoje, o mental e o social se reencontram na prática: no espaço concebido e vivido. Demonstra, assim, a relação dialética entre o espaço mental (percebido, concebido, representado) e o espaço social (construído, produzido, 
projetado). A produção do espaço concebe o espaço racional-funcional-instrumental e o espaço vivido-concebido-mental. ${ }^{3}$

Há, portanto, uma intersecção entre o espaço da representação e a representação do espaço. O espaço, por isso, é ao mesmo tempo ideológico (porque político) e dotado de saber (pois comporta representações elaboradas)". ${ }^{4}$ Pode-se, consequentemente, denominá-lo racional-funcional, sem que tais termos possam separar-se, e funcional-instrumental, pois a função, no quadro global da sociedade "neocapitalista", implica o projeto, a estratégia. Isso demonstra a capacidade que tem o espaço de ser racional-funcional através da "representação do espaço", e funcional-instrumental por ser o "espaço da representação". Existe, em níveis diferentes, um amálgama na produção do espaço entre o espaço da representação e a representação do espaço, no desenvolvimento cada vez mais complexo das relações capitalistas alastradas na espacialidade.

Desse modo, a produção do espaço urbano perpassa pelo cotidiano dos sujeitos que são e produzem o espaço urbano. O cotidiano é elemento fundamental na construção das cidades e nas formas idiossincráticas de produção do espaço urbano, como considera também Carlos (2004). Corrêa (1995, p. 26), por sua vez, afirma que "O espaço é concebido como locus da reprodução das relações sociais de produção, isto é, reprodução da sociedade”, pois, como afirma Lefebvre(1999a, p. 39), "Quem diz 'produção' diz também 'reprodução', ao mesmo tempo, física e social: reprodução de um modo de vida". Ou seja, como material, se (re)produz também um modo de vida, que comporta ideias, sonhos, desejos...

O espaço, então, para Lefebvre, não seria nem um ponto de partida - ao mesmo tempo mental e social, como na hipótese filosófica - nem um ponto de chegada - um produto social ou o lugar dos produtos - mas, e, sobretudo, "um intermediário em todos os sentidos desse termo, ou seja, um modo e um instrumento, um meio e uma mediação" [grifos nossos] (Lefebvre, 2008, p.44). Nessa hipótese, o autor considera que o espaço é um instrumento político intencionalmente manipulado, sendo, por isso, um meio nas mãos de "alguém", grupo, classe, indivíduo, isto é, de um poder (por exemplo, Estado, Igreja), de uma classe dominante (comerciantes, imobiliários, industriais) ou de um grupo político que tanto pode representar a "sociedade" de um município, Estado ou o Mundo, quanto ter seus próprios objetivos, por exemplo.

Como mediação, um espaço pode se tornar instrumental e tanto permitir impor uma aparente e manifesta coesão (pela "violência"), 
quanto mascarar as contradições da realidade (sob uma "atmosfera" de coerência racional e objetiva). Ocorre no espaço uma regulação buscada, pretendida, projetada, o que não quer dizer obtida em sua objetividade, em sua "plenitude". Esse espaço, concomitantemente funcional e instrumental, vincula-se à reprodução da força de trabalho pelo consumo. Na re-produção dos meios de produção faz parte a força de trabalho, pelo trabalho produtivo, que é o motor do consumo de massa. Sendo assim, o espaço na sociedade capitalista é, para Léfèbvre, o meio e o modo, ao mesmo tempo, de uma organização do quadro de consumo (e de vida), cuja reprodução da força de trabalho se manifesta por meio das contradições.

Por isso, a expressão "produção do espaço", provavelmente cunhada por Lefebvreno final dos anos 60, visa responder aos processos de reprodução das relações capitalistas de produção. O espaço para Lefebvreconsiste no lugar onde as relações capitalistas se reproduzem e se localizam com todas as suas manifestações de conflitos, lutas e contradições. Existem, assim, contradições do espaço, mesmo se dissimuladas, escondidas ou mascaradas. As contradições do espaço advêm - para Lefebvre- do conteúdo prático e social e, especificamente, do conteúdo capitalista que, por extensão, expressão a dimensão política da luta, da disputa, do conflito entre, por exemplo, as classes sociais. Nesses termos, o espaço na sociedade capitalista pretende ser racional quando, na prática, é comercializado, despedaçado, vendido em parcelas. Sendo um espaço capitalista, é um espaço seletivo, espaço para aqueles que detêm o poder do consumo, que dá o "direito" à propriedade privada do solo e ao seu uso.

Assim ele é simultaneamente global e pulverizado, vivido e funcional, concebido e vendido, imediato e distante, estratégico e intencional, quadro da reprodução da vida e do consumo. Apresenta, portanto, um caráter paradoxal pois tenta definir um "aqui": junto e ao mesmo tempo separado. É dessa maneira que ele é concomitantemente dominado (pela técnica) e não apropriado (para e pelo uso). Ele é imediato e mediato, ou seja, pertence a uma certa ordem próxima, a ordem da vizinhança, e uma ordem distante, a sociedade, o Estado, o capital.

Por comportar essa problemática, o espaço é eminentemente político. Ele é dotado de intencionalidades e sentidos e por isso é estratégico. Possui uma "ordem", uma ordenação espacial, um arranjo e disposição que visam atingir certos objetivos, certo projeto. $\mathrm{O}$ espaço urbano - mas não só ele - é um projeto, é projeto através de sua instrumentalização técnica, racional e funcional e, amiúde, politicamente conduzido e produzido. 
Nesse contexto, Lefebvre considera em seu livro Espaço e política que $o$ espaço urbano tornou-se o lugar do encontro das coisas, das pessoas e da troca sendo, por isso, fundamental para a reprodução da condição humana. Portanto, excluir do urbano grupos, classes, indivíduos, implica também excluí-los da civilização, até mesmo da sociedade. É fundamental, nesse cenário, a luta pelo direito à cidade. $\mathrm{O}$ direito à cidade, de outros tempos e outros espaços, que não o do consumo e do mercado, que concebe o espaço vivido, o espaço da não segregação e do respeito e convívio com a diferença socioespacial.

O direito à cidade significa, portanto, a constituição ou reconstituição de uma unidade espaço-temporal, de uma reunião, no lugar de uma fragmentação. Ele não elimina os confrontos e as lutas, ao contrário; mas permite, dá o direito que as pessoas possam estabelecer trocas e relações, significa o direito dos cidadãos-citadinos e dos grupos que eles constituem (sobre a base das relações sociais) de figurar sobre "todas" as redes de relações sociais, os circuitos de comunicação, de informação, de trocas, de vivenciar experiências múltiplas no espaço urbano diferentemente produzido e diferencialmente apropriado.

Sobretudo, o livro Espaço e política de Henri Lefebvre é uma imprescindível contribuição para a reflexão e análise da problemática do espaço para aqueles estudiosos seja da Geografia, Sociologia, Filosofia, Arquitetura, História dentre outros que se preocupam com a produção da cidade e do espaço, notadamente do espaço urbano, das suas disputas e conflitos, pois é da política que emerge o espaço para Lefebvre.

\section{Notas}

1 LEFEBVRE, Henri. Le droit à la ville-suivi de Espace et poltique. Paris: Éditions Anthropos, 1972.

2 LEFEBVRE, Henri. La production de l'espace. Paris: Éditions Anthropos, 1974.

3 Lefebvre (1974) desenvolveu plenamente, em livro posterior, essas "duas" características por meio daquilo que ele distingue no processo de produção do espaço como apropriação de dominação ("possessão", "propriedade"); o primeiro, sendo um processo muito mais simbólico, é carregado das marcas do "vivido", do valor de uso; e, o segundo, mais concreto, funcional e vinculado ao valor de troca. Segundo o autor, "O uso reaparece em acentuado conflito com a troca no espaço, pois ele implica 'apropriação' e não 'propriedade'. Ora, a própria apropriação implica tempo e tempos, um ritmo ou ritmos, símbolos e uma prática". Logo, "Tanto mais o espaço é funcionalizado, tanto mais ele é dominado pelos 'agentes' que o manipulam tornando-o unifuncional, menos 
ele se presta à apropriação. Por quê? Porque ele se coloca fora do tempo vivido, aquele dos usuários, tempo diverso e complexo” (Lefebvre, 1974, p. 411-412).

4 A produção do espaço não se limitaria apenas à produção física do capital, mas inclui também a produção da(s) forma(s) de vida da(s) pessoa(s), com suas ideias e representações, pois "A produção em sentido amplo (produção do ser humano por ele mesmo) implica e compreende a produção de ideias, das representações, da linguagem. (...) Os homens produzem as representações, as ideias, mas são 'os homens reais, ativos”” (Lefebvre, 1999b, p. 44). Desse modo, o autor afirma que o conceito de produção é também uma representação porque abarca as relações sociais por meio da auto-reprodução do ser humano, ser social, espacial e temporal. O conceito de produção, nesse sentido, comporta as representações que interpretam as vivências e as práticas: "Las representaciones circulan, pero en torno a fijezas: las instituciones, los símbolos y arquetipos. Interpretan la vivencia y la práctica: intervienen en ellas sin por ello conorcelas ni dominarlas” (Lefebvre, 1983, p. 28). Assim, “(...) as representaciones son productos de la mente humana, de la división social del trabajo. Interpretaciones de la práctica, mutiládola o transponiéndola, se utilizam políticamente” (Lefebvre, 1983, p. 29).

\section{Referências}

CARLOS, Ana Fani. Espaço e tempo sociais no cotidiano. In: . O espaço urbano: novos escritos sobre a cidade. São Paulo: Contexto, 2004. p.59-66.

CORRÊA, Roberto Lobato. Espaço, um conceito-chave da Geografia. In: CASTRO, Iná Elias de; GOMES, Paulo César da C.; CORRÊA, Roberto Lobato. Geografia: conceitos e temas. Rio de Janeiro: Bertrand Brasil, 1995. p.15-47.

LEFEBVRE, Henri. La production de l'espace. Paris: Anthropos,1974. . A cidade do capital. Rio de janeiro: DP\&A, 1999a. . A revolução urbana. Belo Horizonte: Ed. UFMG, $1999 \mathrm{~b}$. . La presencia y la ausencia: contribución a la teoria de las representaciones. México: Fondo de Cultura Económica, 1983. . O direito à cidade. São Paulo: Centauro, 2001. 